\title{
Chenopodium ambrosioides L. extract prevents bone loss ${ }^{1}$
}

\author{
Ciro Dantas Soares', Maria Goretti Freire de Carvalho"I, Rejane Andrade de Carvalho ${ }^{\mathrm{III}}$, Sérgio Rodrigo Pereira Trindade', \\ Amália Cinthia Meneses do Rêgo ${ }^{\text {III, }}$ Irami Araújo-Filho ${ }^{I I I}$, Márcia Martins Marques ${ }^{\mathrm{IV}}$
}

DOI: http://dx.doi.org/10.1590/S0102-865020150120000004

I'Graduate student, Department of Dentistry, Universidade Potiguar (UnP), Natal-RN, Brazil. Conception and design of the study, technical procedures, acquisition and interpretation of data, manuscript preparation.

II PhD, Full Professor, Department of Medicine, (UnP), Natal-RN, Brazil. Conception and design of the study, technical procedures, histopathological examinations, acquisition and interpretation of data, manuscript writing.

IIIFull Professor, Department of Dentistry, (UnP), Natal-RN, Brazil. Conception of the study, intellectual and scientific content of the study, critical revision.

${ }^{\mathrm{IV}} \mathrm{PhD}$, Associate Professor, School of Dentistry, Universidade de São Paulo (USP), Brazil. Conception and design of the study, interpretation of data, manuscript writing, critical revision.

\section{ABSTRACT}

PURPOSE: To evaluate the effect of the Chenopodium ambrosioides L (mastruz) extract for preventing bone loss and bone metabolism in ovariectomized rats.

METHODS: Twelve rats were subjected to bilateral ovariectomy for inducing osteoporosis. After surgery, they were divided into two groups: Ovariectomy-control group $(\mathrm{G} 1, \mathrm{n}=6)$, receiving $0.5 \mathrm{ml}$ distilled water by gavage for 30 days, and Ovariectomy plus mastruz group $(\mathrm{G} 2, \mathrm{n}=6)$, receiving $0.5 \mathrm{ml}$ of the hydroalcoholic extract of mastruz at $10 \%$ concentration ( $50 \mathrm{mg}$ ) daily, for the same period. Then, the blood of the animals was collected for further biochemical analysis (liver function) and tibia and liver were removed for histological and histomorphometric analyses.

RESULTS: The cortical bone was significantly larger in the G2 than G1, whereas G1 presented the highest amount of adipocytes in the bone marrow $(\mathrm{p}<0.05)$. The blood levels of aspartate aminotransferase, triglycerides and cholesterol were significantly higher, whereas globulin and lactate dehydrogenase were smaller in G2 than G1.

CONCLUSION: The hydroalcoholic extract of mastruz has effects on bone metabolism by changing blood proteins and enzymes and preventing both bone loss and the substitution of bone marrow cells by

Key words: Chenopodium ambrosioides. Ovariectomy. Rats. 


\section{Introduction}

Osteoporosis (OP) is a chronic degenerative metabolic bone disease, and is considered a public health problem worldwide, because it affects at least $30 \%$ postmenopausal women across the world $^{1}$. The pathogenesis of OP is very clear and the deleterious effects on bone tissue are because of decreased osteoblast activity and increased osteoclast activation. With the progressive decrease in bone density, the observed effects cause both quantitative and qualitative alterations in the bone tissue ${ }^{2,3}$.

The effect of hormone deficiency is known to be preponderant over bone tissue in postmenopausal OP. Estrogen prevents accelerated bone turnover because diminished levels of estrogen stimulate increased secretion of interleukins (IL-1, IL-6) and tumor necrosis factor (TNF) by monocytes and other bone marrow cells. These cytokines are potent stimulators of recruitment, training, and activation of osteoclasts, causing greater bone resorption ${ }^{4-6}$. This justifies the fact that one in two women suffers a fracture because of postmenopausal $\mathrm{OP}^{7}$. Osteoporosis has financial, physical, and psychosocial consequences that cause significant effects at individual, family, and community levels.

Among the therapeutic options for OP treatment, the bisphosphonates stand out (zoledronate $>$ pamidronate $>$ alendronate $>$ ibandronate $>$ risedronate $>$ etidronate $>$ clodronate, in the order of affinity for bone matrix $)^{8}$. These drugs are associated with an increase in bone mass because they bind to hydroxyapatite crystals. Despite the obvious benefits of treatment with bisphosphonates, they are cytotoxic ${ }^{9,10}$ and its prolonged use has been associated with osteonecrosis ${ }^{11}$, gastroesophageal irritation, and atrial fibrillation ${ }^{12}$. Innovative therapies include selective inhibitors of the receptor activator of nuclear kappa-B ligand (RANKL). These alternatives are costly, making the treatment less accessible and causing a considerable socioeconomic impact. In the United States, the annual costs incurred in OP treatment exceed $\$ 15$ billion $^{13-17}$.

Considering the relevance of the topic, populations in developing nations need to be warned about the increased risk of this chronic disease in postmenopausal women, and there is an emerging need for affordable preventive and therapeutic proposals. Nutritional status and healthy lifestyle are seen as the main forms of preventing osteoporosis ${ }^{18}$. Animal models are useful for evaluating therapeutic methods. The model of ovariectomized rats is of particular importance in this study $1^{9-21}$.

The Ministry of Health, in February 2009, released the List of Medicinal Plants of Interest to the SUS (RENISUS), among which Chenopodium ambrosioides L. (mastruz) was considered the most widely used herbal medicine, by the population ${ }^{22}$. Mastruz is a medicinal plant used worldwide. Studies have proved their anthelmintic, anti-inflammatory, and analgesic activities ${ }^{23,24}$. The main advantages of using phytotherapics are accessibility (cost and availability) and decreased adverse effects, compared with conventional drugs.

Bioactive compounds, such as flavonoids, monoterpenes, and other compounds, all of which are found in hydroalcoholic extracts of phytotherapics, have been indicated for treating OP ${ }^{25-29}$. This indicates that they are very promising avenue for research. However, despite their benefits, hepatotoxic effects have been reported with the use of herbal medicines in rats, probably due to the alcohol in their composition ${ }^{30}$.

Therefore, in this study, the effects of administering mastruz extract in rats with induced OP were evaluated by means of histological and biochemical analyses.

\section{Methods}

The experimental protocol was approved by the Ethics Committee (CEP/UNP) (number 007/2013). This protocol followed the guidelines of the Animal Experimentation Code of Ethics and Brazilian College of Animal Experimentation.

Twelve Wistar rats with a mean age of 90 days (body weight, $200 \mathrm{~g} \pm 50 \mathrm{~g}$ ) provided by the animal facility of the Potiguar University were kept in an environment with appropriate light (cycles of $12 \mathrm{~h}$ light/dark), ventilation and temperature $\left(24^{\circ} \mathrm{C}\right)$. The animals were fed with a balanced diet (Labina ${ }^{\circledR}$ Purina) and water ad libitum.

\section{Preparation of the plant extract}

Fresh plants of C. ambrosioides L. were collected and placed in a drying oven for three days. The plants were then homogenized and ethanol in a 1:3 ratio was added for the percolation process. The material was filtered and concentrated in rotary evaporator at a constant temperature of $60^{\circ} \mathrm{C}$. The concentrated extract was weighed and diluted with distilled water, and a hydroalcoholic extract of mastruz at a concentration of $10 \%$ was obtained. This extract was kept in the refrigerator $\left(5^{\circ} \mathrm{C}\right)$ and all experiments were performed before the end of validity of the product.

\section{Induction of the osteroporosis}

Bilateral ovariectomy was performed for the induction of osteoporosis in all animals. After surgery, the animals were 
divided into two groups: the ovariectomy-control group (G1, $\mathrm{n}=$ 6), which received $0.5 \mathrm{ml}$ distilled water by gavage for 30 days, and the ovariectomy-mastruz group $(\mathrm{G} 2, \mathrm{n}=6)$, which received $0.5 \mathrm{ml}$ of the mastruz extract at a concentration of $10 \%(50 \mathrm{mg})$ daily, by the same period. The sample size was based in previous reports $^{25,30}$.

For the ovariectomy the animals were anesthetized using a Zoletil 50 solution (Virbac, São Paulo, Brazil) injected intramuscularly (IM) at a dose of $0.3 \mathrm{~mL} / 100 \mathrm{mg}$ in the quadriceps region. After anesthesia, the anterior abdominal region and hypogastrium were shaved, and antisepsis was ensured with $2 \%$ chlorhexidine solution. This was followed by a $3-\mathrm{cm}$ longitudinal incision on the abdominal wall for exposing the uterus and ovaries. After identifying the ovaries, the mesovarium was bilaterally

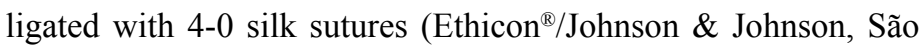
Paulo, Brazil) and bilateral ovariectomy was performed after ensuring hemostasis. At the end of the procedure, the abdominal wall was closed with a Polydioxanone 4-0 suture (Ethicon ${ }^{\circledR} /$ Johnson \& Johnson) and the skin sutured with 4-0 nylon (Ethicon ${ }^{\circledR /}$ Johnson \& Johnson). Metamizol $0.5 \mathrm{mg} / \mathrm{kg}$ (Roche Pharm ${ }^{\circledR}$, São Paulo, Brazil) was administered orally once a day for 3 days for preventing postoperative pain. Both groups remained under postoperative observation for 10 days, during which the weight alterations were measured in a weighing scale.

\section{Bioassay}

Treatments were established $24 \mathrm{~h}$ after completing bilateral ovariectomy. Accordingly, the animals received distilled water (G1) and mastruz extract at a concentration of $50 \mathrm{mg}$ /day (G2) for 30 days by gavage, when the blood of the animals was collected for further biochemical analysis and they were sacrificed.

\section{Histological and histomorphometric analyses}

After sacrificing the animals with overdose of anesthetics, necropsy was performed and sections of liver and femur were taken for further histological analysis. The specimens were fixed in $10 \%$ formalin solution for $48 \mathrm{~h}$, then the femur was decalcified with nitric acid (5\%) for five days, and both tissues were processed according to the standard protocol of the pathology laboratory. Then, 5- $\mu \mathrm{m}$ sections were obtained from paraffin blocks by using a microtome. Tissue sections were mounted onto slides, which were then stained with hematoxylin and eosin (HE). The liver samples were also stained with Masson's trichrome and reticulin.
For microscopic analysis, the slides were analyzed in a binocular light microscope (Olympus CX31 model, Hamburg, Germany) with an attached camera. Photomicrographs of the various microscopic fields were taken at different magnifications (x40, x100, or x400). Liver morphology was analyzed in sections stained by the three dyes.

Histomorphometry was performed in the femur (one field for each sample at magnification of $\mathrm{x} 40$ ) to analyze the cortical bone area, in standardized region for all animals and groups (center of diaphysis of the femur). The adipocytes (these cells are easily identified by conventional microscopy) were quantified in the bone marrow in photomicrographs that were analyzed using the tool “Count Cell” of the Image $\mathrm{J}^{\circledR}$ software (NIH, Bethesda, USA), according to the methodology earlier reported by Egan et al. ${ }^{31}$. To determine the cortical area, the total area of bone and bone marrow in the microscopic fields were calculated. The cortical area was obtained after subtracting the bone marrow from the total area, which was represented by the formula described below. These data were tabulated in Excel (Microsoft ${ }^{\circledR}$, WA, USA) software.

Formula: CORTICAL BONE AREA = TOTAL SUFARCE OF BONE - AREA OF BONE MARROW

\section{Biochemical analysis}

The blood of the rats was collected by cardiac puncture for further biochemical analysis. Biochemical parameters were measured in the autoanalyzer spectrophotometer $\left(60 \mathrm{i} \mathrm{Konelab}^{\circledR}\right.$, Software Version, Finland) of the Laboratory of Clinical Analyses, Potiguar University. Serum levels of alanine aminotransferase (ALT), lactate dehydrogenase (LDH), aspartate aminotransferase (AST), cholesterol and its fractions (low-density lipoprotein cholesterol and high-density lipoprotein cholesterol), glucose, creatinine, triglycerides, total protein and its fractions (albumin and globulin) were measured using an assay kit (Weiner ${ }^{\circledR}$, São Paulo, Brazil).

\section{Statistical analisys}

Firstly the Kolmogorov-Smirnov test was done showing that the data sets showed normal distribution. Then, for comparison of the two groups the Student's t test was selected (parametric test). All tests were performed in the GraphPad Prism 5.0 software (GraphPad Software Inc., La Jolla, CA, USA) with a significance level of $95 \%$. 


\section{Results}

Histomorphometry of the cortical bone of the femur

The mean cortical areas of the femurs ranged from 169.3 to 228.7 in the ovariectomy-control group and from 219.4 to 302.3 $\left(\mu \mathrm{m}^{2}\right)$ in the ovariectomy plus mastruz group, as shown in Figure 1. The femur cortical areas of rats treated with mastruz were significantly larger than those of ovariectomy-control animals (Student's t test, $\mathrm{p}<0.05$ ).

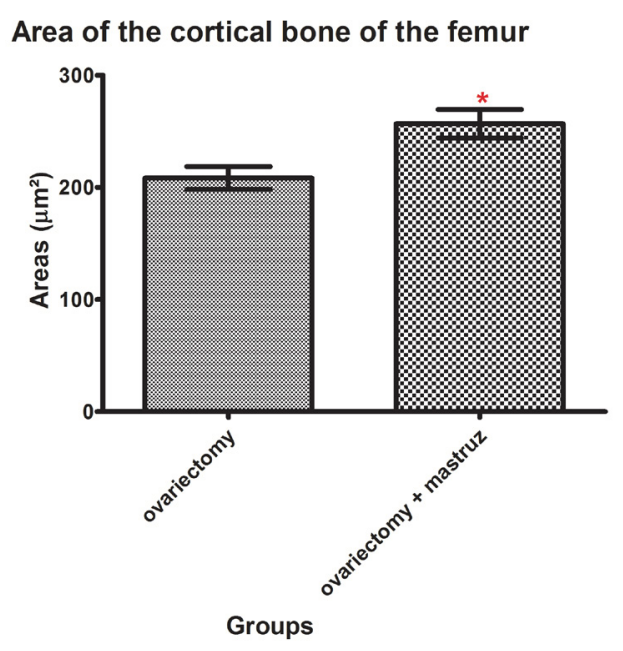

FIGURE 1 - Graphic representation of the mean area $\left(\mu \mathrm{m}^{2}\right)$ of cortical bone of femurs in rats treated or not with mastruz. *Significantly larger than control $(\mathrm{p}<0.05)$. (Bars indicate: standard deviation).

\section{Histological analysis of the bone marrow}

The Figure 2 illustrates the histological aspects of the femur of rats from both groups. The bone marrow of rats from ovariectomy plus mastruz group (Figure 2A) were represented by a cellularized tissue with scarce adipocytes; whereas ovariectomycontrol rats presented larger amounts of adipose tissue permeating the bone marrow of the femur (Figure 2B).

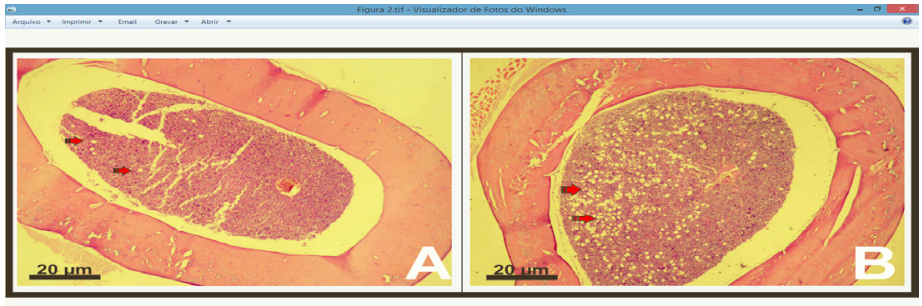

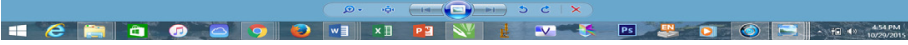

FIGURE 2 - Photomicrographs of transversal sections of femur of rats from the ovariectomy plus mastruz group (A) and the control group (B). Adipose tissue (arrows) are present in the bone marrow, especially in the control group (B). (Original magnification $\mathrm{x} 40$ ).
The bone marrow showed significantly higher adipocyte numbers in the ovariectomy-control group (Student's t test, $\mathrm{p}<0.05$ ) (Figure 3 ) than in the ovariectomy plus mastruz group.

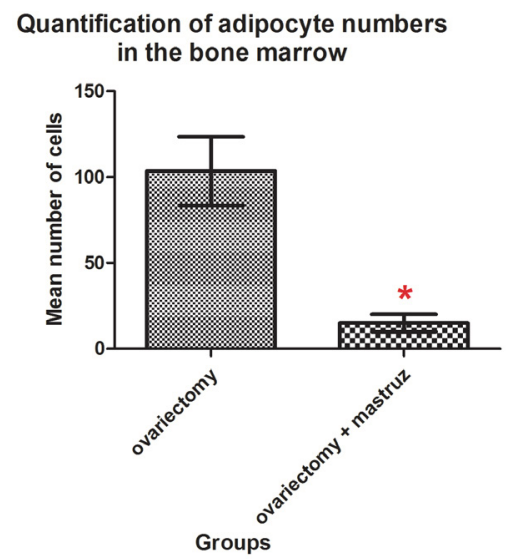

FIGURE 3 - Graphic representation of the mean number of adipocyte in the bone marrow of both experimental groups. *Significantly larger than control $(\mathrm{p}<0.05)$. (Bars indicate standard deviation).

\section{Histological analysis of the liver}

As seen in Figure 4, the liver of the animals of the ovariectomy-control and ovariectomy plus mastruz groups showed only occasional alterations.

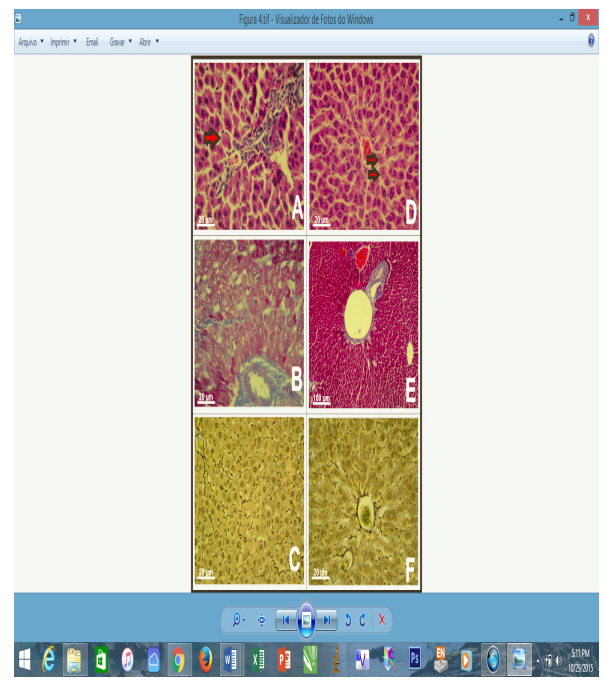

FIGURE 4 - Photomicrographs of liver of rats in ovariectomy group. A: normal architecture of hepatocytes, with some features of reversible lesions (HE, original magnification $\mathrm{x} 400$ ); B: absence of fibrosis (Masson's trichrome, original magnification $\mathrm{x} 400$ ) and $\mathbf{C}$ : normal distribution of reticular fibers (reticulin stain, original magnification $\mathrm{x} 400$ ). Photomicrographs of liver of rats in ovariectomy plus mastruz group. Aspects similar to the liver of rats in the control group: D (HE, original magnification $\mathrm{x} 400$ ), E (Masson's trichrome, original magnification $\mathrm{x} 100$ ), and $\mathrm{F}$ (reticulin stain, original magnification $\mathrm{x} 400$ ). Areas of coagulation necrosis (red arrows). 


\section{Biochemical parameters}

The results of the serological tests are shown in Table 1. The blood levels of aspartate aminotransferase, triglycerides and cholesterol were significantly higher, whereas globulin and lactate dehydrogenase were smaller in ovariectomy plus mastruz group than in ovariectomy-control group $(\mathrm{p}<0.05)$. Alkaline phosphatase, glucose and minerals (calcium, phosphorus and magnesium) were similar in both groups $(\mathrm{p}>0.05)$.

TABLE 1 - Biochemical parameters in the control group and treated with mastruz. (Mean \pm standard deviation).

\begin{tabular}{cccc}
\hline Parameter & Ovariectomy (Control group) & Ovariectomy plus mastruz & P value \\
\hline Aspartate aminotransferase (U/L) & $132.2 \pm 15.61$ & $246.2 \pm 33.19$ & $0.0111^{*}$ \\
Globulin (g/dL) & $4.470 \pm 0.2720$ & $1.783 \pm 0.1869$ & $<0.0001^{*}$ \\
Lactate dehydrogenase (U/L) & $2539 \pm 754.3$ & $602.7 \pm 36.42$ & $0.0282^{*}$ \\
Alkaline phosphatase & $203.6 \pm 7.80$ & $163.6 \pm 26.00$ & 0.1788 \\
Glucose (mg/dL) & $147.0 \pm 13.63$ & $110.2 \pm 12.31$ & 0.0727 \\
Triglycerides (mg/dL) & $24.33 \pm 1.764$ & $57.17 \pm 2.455$ & $0.0287 *$ \\
Cholesterol (mg/dL) & $67.50 \pm 5.340$ & $84.67 \pm 4.088$ & 0.8104 \\
Calcium (mg/dL) & $9.917 \pm 0.63$ & $9.983 \pm 0.19$ & 0.0732 \\
Phosphorus (mg/dL) & $14.57 \pm 2.68$ & $9.133 \pm 0.39$ & $2.883 \pm 0.12$ \\
Magnesium (mg/dL) & $3.333 \pm 0.32$ & 0.2256 \\
\hline
\end{tabular}

*Statistically significant differences between both groups $(\mathrm{p}<0.05)$.

\section{Discussion}

In this study a model of osteoporosis induced by ovariectomy was used. This model is widely applied in the scientific literature, because it simulates the effects of estrogen deficiency on bone tissue. Considering that most menopausal women may have an alteration in bone metabolism (osteopenia or osteoporosis), understanding these mechanisms and proposing a prevention strategy is extremely important $\mathrm{t}^{20,25,32}$.

C. ambrosioides $\mathrm{L}$. is considered to be the most commonly used medicinal plant, but more studies are needed to validate its use for therapeutic purposes. Phytochemical studies revealed a variable amount of flavonoids and monoterpenes in its extract. These bioactive compounds generally exhibit anti-inflammatory activities, which indicate its use for preventing osteoporosis ${ }^{22-24}$.

The most striking finding of this study was the significant increased cortical area of the femur in the ovariectomy plus mastruz group in comparison with the control group $(p<0.05)$. Additionally, the bone marrow of treated rats was preserved showing high cellularity in opposition to the adipose tissue deposition observed in the control group. Besides these histological indications of the beneficial effects of mastruz in preserving the bone structure in the ovariectomized rats, some blood tests indicated higher cell metabolism in these animals. In fact, their blood levels of triglycerides and cholesterol were higher than those of the control animals. Triglycerides are considered as a type of fuel, while cholesterol is needed for building cells and their increases are consonant with increase of osteoblasts proliferation and synthesis, which resulted in the cortical bone increase. These data corroborate the findings of Pereira et $a l .^{33}$, who evaluated animal organs, including the bone marrow, in a toxicity model of continuous treatment with mastruz. They concluded that treatment with mastruz at higher doses was able to stimulate cell proliferation in the bone marrow of animals.

Recent studies indicate that adipogenesis and osteogenesis mediated by the differentiation of mesenchymal stem cells that occur in the bone marrow are in perfect balance. However, osteogenesis is suppressed when adipocyte formation is induced $^{34,35}$. In the present study, it can be observed that the bone marrow of the animals treated with mastruz showed higher number of native bone marrow cells, whereas the adipocyte numbers were lower. Thus, we suggest that a possible mechanism of action of mastruz is the activation of osteogenesis and suppression of adipogenesis, which would imply a higher number of osteoblasts, and consequently greater bone formation. We found no published studies that evaluated the presence of adipocytes in the bone marrow of rats under antiosteoporotic therapy, which confirms the relevance of this study. Further studies are being conducted by our group in order to clarify these questions.

It is known that herbal medicines may have adverse effects, especially when used indiscriminately and when they are not regulated by the appropriate authorities ${ }^{30}$. Knowing that most drugs are metabolized in the liver, in the present study this organ was histologically analyzed. Additionally, some blood tests able to 
evaluate liver condition were done. Liver enzymes, such as Alanine transaminase (ALT) and Aspartate transaminase (AST) when elevated may indicate inflammation or damage to cells in the liver, once they are related to the cellular integrity. Although, not specific to liver cells, the Lactate dehydrogenase (LDH) also indicates cellular damage. Serum glucose, globulin, as well as Alkaline phosphatase (ALP) levels in the blood may also be related to liver function. Hepatic lesions can impair the gluconeogenesis in the liver. On the other hand, large bile duct obstruction, intrahepatic cholestasis, or infiltrative diseases of the liver will lead to increased ALP levels in plasma. We have found that blood levels of AST were higher and the glucose levels smaller in the ovariectomy plus mastruz group than in ovariectomy-control. These findings would indicate a hepatotoxic effect of mastruz; however, the histological analysis of the liver did not confirm this hypothesis, once livers of both groups presented similar histomorphology. Coagulation necrosis was observed in only some animals of both groups, which could be an intrinsic characteristic of this organ related to the age of the animals, or even to the osteoporosis itself. Moreover, LDH levels were diminished in the ovariectomy plus mastruz group showing an overall less cellular damage to these rats than to the ovariectomy-control rats. Additionally, glucose as well ALP blood levels were similar in both groups. Thus, the glucogenesis was not impaired and the liver was not damaged enough to alter the ALP blood level. Taken altogether, there the mastruz extract seemed to be non hepatotoxic, at least in the concentration here applied.

Even with evident histological and histomorphometric alterations, treatment with the mastruz extract did not change serum levels of calcium, phosphorus, and magnesium. This suggests that the mechanism of action of this herbal medicine is probably at the cellular level, with osteoblast activation and osteoclast inhibition rather than in the metabolism of minerals. It has been reported that flavonoids extracted from medicinal plants may assist in osteoblast activation by binding to the estrogen receptors in these cells ${ }^{36}$.

\section{Conclusion}

The hydroalcoholic extract of mastruz has effects on bone metabolism by changing blood proteins and enzymes and preventing both bone loss and the substitution of bone marrow cells by adipocytes in ovariectomized rats.

\section{References}

1. Leslie WD, Morin SN. Osteoporosis epidemiology 2013: implications for diagnosis, risk assessment, and treatment. Curr Opin Rheumatol. 2014 Jul;26(4):440-6. doi: 10.1097/BOR.0000000000000064.
2. Seeman E. Pathogenesis of bone fragility in women and men. Lancet. 2002 May 25;359(9320):1841-50. Review. PMID: 12044392.

3. Raisz LG Pathogenesis of osteoporosis: concepts, conflicts, and prospects. J Clin Invest. 2005 Dec;115(12):3318-25. PMID: 16322775.

4. Pacifici R. Estrogen, cytokines, and pathogenesis of postmenopausal osteoporosis. J Bone Miner Res. 1996 Aug;11(8):1043-51. Review. PMID: 8854239.

5. Papanicolaou DA, Wilder RL, Manolagas SC, Chrousos GP. The pathophysiologic roles of interleukin-6 in human disease. Ann Intern Med. 1998 Jan 15;128(2):127-37. PMID: 9441573.

6. Chen G, Goeddel DV. TNF-R1 signaling: a beautiful pathway. Science. 2002 May 31;296(5573):1634-5. PMID: 12040173.

7. de Oliveira Ferreira N, da Silva RB, Arthuso M, Pinto-Neto AM, Caserta N, Costa-Paiva L. Prevalence of vertebral fractures and quality of life in a sample of postmenopausal Brazilian women with osteoporosis. Arch Osteoporos. 2012;7:101-6. doi: 10.1007/s11657012-0086-z.

8. Drake MT, Clarke BL, Khosla S. Bisphosphonates: mechanism of action and role in clinical practice. Mayo Clin Proc. 2008 Sep;83(9):1032-45. doi: 10.4065/83.9.1032.

9. Correia Vde F, Caldeira CL, Marques MM. Cytotoxicity evaluation of sodium alendronate on cultured human periodontal ligament fibroblasts. Dent Traumatol. 2006 Dec;22(6):312-7. PMID: 17073923.

10. Moreira MS, Katayama E, Bombana AC, Marques MM. Cytotoxicity analysis of alendronate on cultured endothelial cells and subcutaneous tissue. a pilot study. Dent Traumatol. 2005 Dec;21(6):329-35. PMID: 16262618.

11. Brozoski MA, Traina AA, Deboni MC, Marques MM, NaclérioHomem Mda G. Bisphosphonate-related osteonecrosis of the jaw. Rev Bras Reumatol. 2012 Mar-Apr;52(2):265-70. PMID: 22460415.

12. Martins MA, Martins MD, Lascala CA, Curi MM, Migliorati CA, Tenis CA, Marques MM. Association of laser phototherapy with PRP improves healing of bisphosphonate-related osteonecrosis of the jaws in cancer patients: a preliminary study. Oral Oncol. 2012 Jan;48(1):79-84. doi: 10.1016/j.oraloncology.2011.08.010.

13. Honig S. Osteoporosis - new treatments and updates. Bull NYU Hosp Jt Dis. 2010;68(3):166-70. PMID: 20969546.

14. Griffith JF, Genant HK. New advances in imaging osteoporosis and its complications. Endocrine. 2012 Aug;42(1):39-51. doi: 10.1007/ s12020-012-9691-2.

15. Brown JP, Reid IR, Wagman RB, Kendler D, Miller PD, Jensen JE, Bolognese MA, Daizadeh N, Valter I, Zerbini CA, Dempster DW. Effects of up to 5 years of denosumab treatment on bone histology and histomorphometry: the FREEDOM study extension. J Bone Miner Res. 2014 Sep;29(9):2051-6. doi: 10.1002/jbmr.2236.

16. Cosman F. Combination therapy for osteoporosis: a reappraisal. Bonekey Rep. 2014 Apr 2;3:518.

17. Ristow O, Gerngroß C, Schwaiger M, Hohlweg-Majert B, Kehl V, Jansen H, Hahnefeld L, Koerdt S, Otto S, Pautke C. Effect of antiresorptive drugs on bony turnover in the jaw: denosumab compared with bisphosphonates. Br J Oral Maxillofac Surg. 2014 Apr;52(4):308-13. doi: 10.1016/j.bjoms.2014.01.021.

18. NIH Consensus Development Panel on Osteoporosis Prevention, Diagnosis, and Therapy. Osteoporosis prevention, diagnosis, and therapy. JAMA. 2001 Feb 14;285(6):785-95. PMID: 11176917.

19. Atmaca H, Aydın A, Musaoğlu R. Experimental model of osteoporosis: comparison between ovariectomy and botulinum toxin a. Acta Ortop Bras. 2013;21(6):340-3. doi: 10.1590/S141378522013000600009.

20. Zheng YY, Yang J, Chen DH, Sun L. Effects of the stilbene extracts from Cajanus cajan L. on ovariectomy-induced bone loss in rats. Yao Xue Xue Bao. 2007 May;42(5):562-5. PMID: 17703784. 
21. Xu J, Rong H, Ji H, Wang D, Wang J, Zhang W, Zhang Y. Effects of different dosages of parathyroid hormone-related protein 1-34 on the bone metabolism of the ovariectomized rat model of osteoporosis. Calcif Tissue Int. 2013 Sep;93(3):276-87. doi: 10.1007/s00223-0139755-1.

22. TrivellatoGrassi L, Malheiros A, Meyre-Silva C, Buss Zda S, Monguilhott ED, Fröde TS, da Silva KA, de Souza MM. From popular use to pharmacological validation: a study of the antiinflammatory, anti-nociceptive and healing effects of Chenopodium ambrosioides extract. J Ethnopharmacol. 2013 Jan 9;145(1):127-38. doi: 10.1016/j.jep.2012.10.040.

23. Kiuchi F, Itano Y, Uchiyama N, Honda G, Tsubouchi A, NakajimaShimada J, Aoki T. Monoterpene hydroperoxides with trypanocidal activity from Chenopodium ambrosioides. J Nat Prod. 2002 Apr;65(4):509-12.

24. Kumar R, Mishra AK, Dubey NK, Tripathi YB. Evaluation of Chenopodium ambrosioides oil as a potential source of antifungal, antiaflatoxigenic and antioxidant activity. Int J Food Microbiol. 2007 Apr 10;115(2):159-64. PMID: 17174000.

25. Xing GS, Lou JS, Wang ZB, Yu SL, Wang Y, Sheng L. Effects of Dioscorea septemloba on bone metabolism in ovariectomized rats. Zhongguo Zhong Yao Za Zhi. 2007 Sep;32(18):1909-13. PMID: 18051905.

26. Zhao H, Li X, Li N, Liu T, Liu J, Li Z, Xiao H, Li J.Long-term resveratrol treatment prevents ovariectomy-induced osteopenia in rats without hyperplastic effects on the uterus. Br J Nutr. 2014 Mar 14;111(5):836-46. doi: 10.1017/S0007114513003115.

27. Uehara K, Takahashi A, Watanabe M, Nomura Y. Shark protein improves bone mineral density in ovariectomized rats and inhibits osteoclast differentiation. Nutrition. 2014 Jun;30(6):719-25. doi: 10.1016/j.nut.2013.11.005.

28. Tsuang YH, Chen LT, Chiang CJ, Wu LC, Chiang YF, Chen PY, Sun JS, Wang CC. Isoflavones prevent bone loss following ovariectomy in young adult rats. J Orthop Surg Res. 2008 Mar 2;3:12. doi: 10.1186/1749-799X-3-12.

29. Khedgikar V, Gautam J, Kushwaha P, Kumar A, Nagar GK, Dixit P, Chillara R, Voruganti S, Singh SP, Uddin W, Jain GK, Singh D, Maurya R, Chattopadhyay N, Trivedi R. A standardized phytopreparation from an Indian medicinal plant (Dalbergia sissoo) has antiresorptive and bone-forming effects on a postmenopausal osteoporosis model of rat. Menopause. 2012 Dec;19(12):1336-46. doi: 10.1097/gme.0b013e318256b6ae.
30. Holanda CM, Barbosa DA, Demeda VF, Bandeira FT, Medeiros HC, Pereira KR, Barbosa VS, Medeiros AC. Influence of Annona muricata (soursop) on biodistribution of radiopharmaceuticals in rats. Acta Cir Bras. 2014 Mar;29(3):145-50. doi: 10.1590/S010286502014000300001.

31. Egan KP, Brennan TA, Pignolo RJ. Bone histomorphometry using free and commonly available software. Histopathology. 2012 Dec;61(6):1168-73. doi: 10.1111/j.1365-2559.2012.04333.x.

32. Sun W, Wang YQ, Yan Q, Lu R, Shi B. Effects of Er-Zhi-Wan on microarchitecture and regulation of $\mathrm{Wnt} / \beta$-catenin signaling pathway in alveolar bone of ovariectomized rats. J Huazhong Univ Sci Technolog Med Sci. 2014 Feb;34(1):114-9. doi: 10.1007/ s11596-014-1241-0.

33. Pereira WS, Ribeiro BP, Sousa AI, Serra IC, Mattar NS, Fortes TS, Reis AS, Silva LA, Barroqueiro ES, Guerra RN, Nascimento FR. Evaluation of the subchronic toxicity of oral treatment with Chenopodium ambrosioides in mice. J Ethnopharmacol. $2010 \mathrm{Feb}$ 17;127(3):602-5. doi: 10.1016/j.jep.2009.12.018.

34. Nuttall ME, Shah F, Singh V, Thomas-Porch C, Frazier T, Gimble JM. Adipocytes and the regulation of bone remodeling: a balancing act. Calcif Tissue Int. 2014 Jan;94(1):78-87. doi: 10.1007/s00223013-9807-6.

\section{Correspondence:}

Márcia Martins Marques

Faculdade de Odontologia-Universidade de São Paulo

Avenida Professor Lineu Prestes, 2227

05508-000 São Paulo - SP Brasil

mmmarques@usp.br

Received: Aug 25, 2015

Review: Oct 20, 2015

Accepted: Nov 17, 2015

Conflict of interest: none

Financial source: CNPq (Grant No 117277/2014-2)

${ }^{1}$ Research performed at Laboratory of Pathology, Universidade Potiguar (UnP), Natal-RN, Brazil. 